\title{
Information System Innovation as a Social Action: The Case of Career and Vocational Helping Systems
}

\author{
Sy-Feng Wang, ${ }^{1}$ Hsin-Peng Shiahhou, ${ }^{2}$ Ji-Tsung Ben Wu, ${ }^{3}$ and Chaoming Liu ${ }^{1}$ \\ 1 Department of Psychology, Fu-Jen Catholic University, Taiwan ROC \\ 2 Department of Business Administration, Fu-Jen Catholic University, Taiwan ROC \\ 3 Department of Information Management, Fu-Jen Catholic University, Taiwan ROC
}

\begin{abstract}
$\mathrm{n}$ the past 10 years, under the common problems of unemployment of people with a higher education and the devaluation of diplomas, the concepts and practices of higher education governance have emerged and have gradually been embedded in university operations. Higher education in Taiwan faces the same problems as the rest of the world. Thus, guided by policies of the Taiwanese Ministry of Education (TMOE) and fuelled by the media, the education-job gap is becoming a discursive truth. With this background, the TMOE has invested numerous resources to establish an information system (IS) that attempts to guide the direction of university education using information technology. If the IS is poorly designed, the scope of its side effects and harm will be magnified by a massive number of IS users and the characteristics of procedure standardisation. We suggest another form of action - IS competition, in which more positive social changes can be created. Based on the analysis of the available data, the action of IS competition does have a positive impact on society.
\end{abstract}

Keywords: disciplinary technology, information system, career and vocational helping systems

In the past 10 years, under the common problems of the unemployment of people with a higher education and the devaluation of diplomas, concepts and practices of higher education governance have emerged, such as employability (Harvey, 2001), competence-based education (Frank et al., 2010), and higher education evaluation and accreditation (Kehm, 2010), and these concepts have gradually been embedded in university operations. Since information systems (ISs) can deal with complicated affairs, the information technology of higher education is included in this wave of higher education governance. With the progress of the wave, university professors are realising that the forms of curriculum outlines have become more and more complicated. There are increased options and charts in the forms of course outlines, academic and service activities, and learning portfolios. In addition, performance indices now include the number of interns, employment rate and tracking of graduates. Generally speaking, in the New Liberalism stream of thought, educational authorities tend to consider and regulate schools and students through competition in the global economic production system; and ISs have gradually become management tools to discipline schools and students within higher education governance.
According to Foucault (1982), a social governance system includes a legitimacy base that comes from the mutual production of power and knowledge and a variety of governance practices that are foundationally supported by this legitimacy. However, in the process of gaining a legitimacy base, a number of unreasonable governance practices may also be implanted. These irrational practices will not help solve the problem, and they may even cause more problems, side effects and harm. Modern society is a society of information, in which information and communication technology (ICT) has become an important part of the social structure. ISs are an important and nearly indispensable means of governance in the operation of modern society and organisations. If the IS is poorly designed, the scope of its side effects will be magnified by a massive number of IS users and the characteristics of procedure standardisation. When it is applied in educational governance, it can result in more significantly negative effects.

Regarding governmental environments with an inappropriate IS, past literature has indicated two possible actions: challenge or divert. We used a higher education IS as an example and attempted to develop a third action. The purpose was to design and develop another IS that could match the needs of higher education and students' needs.

Address for correspondence: Hsin-Peng Shiahhou, Department of Business Administration, Fu-Jen Catholic University, 510 Chung Cheng Rd, Hsinchuang, Taipei County 24205 Taiwan ROC. E-mail: 051525@mail.fju.edu.tw 
More active action is practised by introducing competition between ISs. The rest of this study is organised as follows. After the literature review, we explain the background of the construction of a new IS, the Career and Competency Assessment Network (UCAN), by the government of Taiwan and then, from the perspective of Foucault (1981, 1982), we analyse and interpret two negative effects of the UCAN. The action and results are then explained, including the design concept and effectiveness of the development of a competing IS (Career \& Vocational Helping System; CVHS) to the government's model. Finally, the results of the competition between CVHS and UCAN are outlined, and the action outcomes are discussed.

\section{Disciplinary Technology}

Based on Foucault-related concepts, Willcocks (2006) systematically reviewed the literature in the information field. Using Foucault's notions of self-discipline, Doolin (1998) proposed the concept of disciplinary technology in the IS field. The main purpose was to explain the effect of the introduction of a casemix IS in hospitals. A casemix IS connects cases of illness, prescriptions, and related costs. From the macro-perspective, management can control managerial information such as resources and costs, and then design managerial policy according to the costs. From the micro-perspective, the system quantifies and normalises the costs of medical activities. Hence, when medical professions select a diagnosis and medical plan, they not only consider the patient's physical conditions and medical treatment, but also the cost of medical activities and positions in the norm. Therefore, by using quantification and norm comparisons, the medical profession can evaluate cost efficiency and thereby form self-monitoring and self-discipline governance. In other words, information technology is both the management information system and the disciplinary technology.

In a modern, complicated society, social governance cannot avoid self-discipline. Self- disciplinary technology is not entirely negative, but the assumptions and conditions of disciplinary technology might only suit mainstream groups rather than other groups. Disciplinary technology might suppress or harm marginal groups that do not fit mainstream IS assumptions. For instance, Avgerou and McGrath (2007) suggested that IS innovation should not be based only on technical and rational perspectives. It should be concerned about the value, benefits and power of the IS for different groups. From this perspective, when examining and evaluating disciplinary technology, we should not only observe the internal quality of the system but also analyse its impact on different external groups.

In addition, according to Foucault (1982), social governance systems are associated with the mutual production of power and knowledge. When management governs with a disciplinary technology, it will reinforce and stabilise the legitimacy of the existing knowledge-power base; the underlying discourses are not questioned, thus avoiding consideration of other possible solutions.

Doolin (1998) indicated two possible actions for disciplinary technology. One was to challenge the causal and calculating logic of the IS. For instance, in casemix IS, clinicians resisted the system by challenging the validity of the case mix information, or by pointing to other factors that potentially could explain clinical outliers or variances between individual clinicians' practices. Another kind of action may appropriate and manipulate the information and rhetoric of the IS, thereby diverting disciplinary practices to their own end. For instance, in casemix IS, some experienced clinicians fought for additional resources using the information it provided.

\section{Disciplinary Technology in Higher Education: A Case from Taiwan}

The problems encountered by higher education in Taiwan are the same as those encountered in other parts of the world. They include increasing unemployment rates, atypical employment environments, and long-term low and even reduced salaries. However, Taiwan also deals with past mistakes in its policies. Since the implementation of the university expansion and an upgraded policy in 1997, the number of universities has increased from 24 to 122 (for a total population of 23.4 million), and the percentage of the 20- to 24-year-old population who has received a post-secondary education has increased from $25 \%$ in 1997 to $71 \%$ in 2012 . The relative weights of academic and vocational systems have also changed. Therefore, the problems of higher education in Taiwan not only include similarities with other countries and the gap between school education and practical application (ability mismatches between school and occupation), but also refer to unique local causes, particularly the supply and demand disequilibrium resulting from an excess number of higher education graduates.

There has been social pressure for the Taiwan Ministry of Education (TMOE) to take action. Nevertheless, it is much more difficult to deal with the supply and demand disequilibrium than the gap between school education and practical application. Therefore, most of the government's policies have been based on the gap between school education and practical application (e.g., learning outcome-based department evaluations, competencebased educational systems, and quality control systems). It has neglected the basic problems arising from the supply and demand disequilibrium. Hence, due to the policy of the TMOE and media reports, the gap between school education and practical application has become a discursive truth. Based on this, the TMOE invested a great amount of resources and authorised the Industrial Technology Research Institute to establish the UCAN IS in order to guide university education using information technology.

The basic framework of the UCAN is based on the Career Clusters ${ }^{\mathrm{TM}}$ (http://www.careertech.org/ 


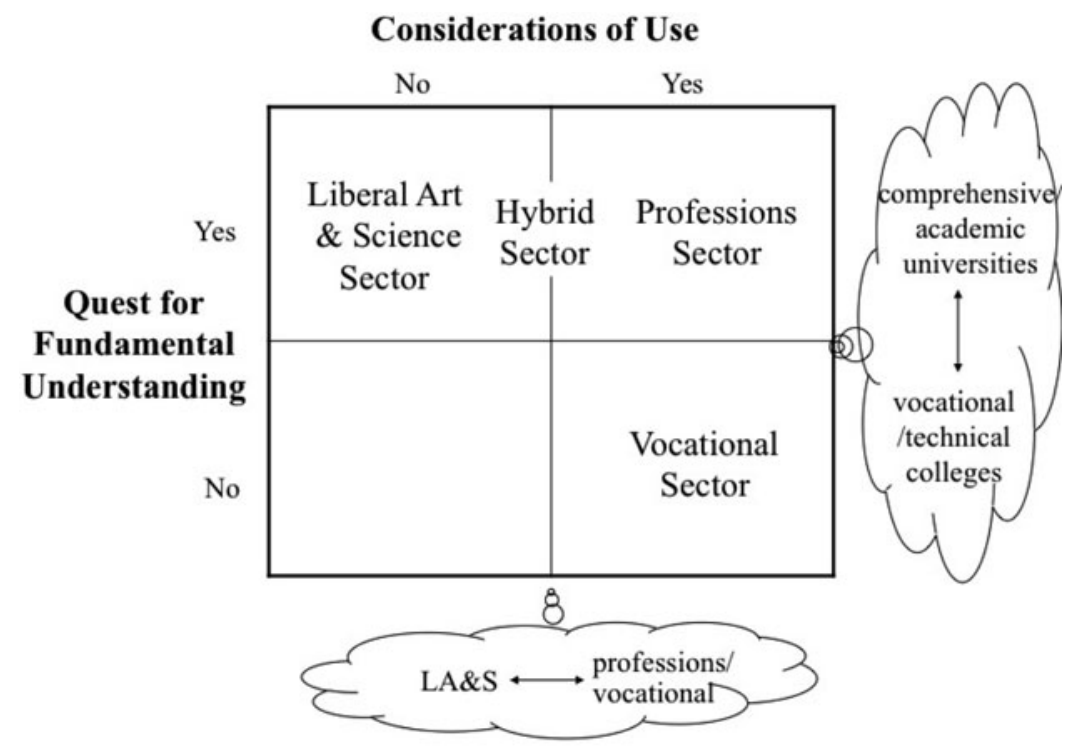

\section{Figure 1}

Different higher education modes and their underlying dimensions.

career-clusters/) of the National Association of State Directors of Career Technical Education Consortium (NASDCTEc) in the United States. It classifies occupations corresponding to the U.S. vocational system into 16 categories of career clusters and 73 types of career pathways and acts as an organising tool for curriculum design and instruction. Program designs can thus match certain types of pathways, while vocational and technological programs can match clusters and pathways. This provides a way to connect secondary and post-secondary curricula and allows limited resources to be used more precisely.

The higher education system can be divided into different sectors depending on their nature, such as the liberal arts and sciences (LA\&S), the professions, a hybrid of the LA\&S and professions, and vocational/technical education. These four sectors can be roughly distinguished according to the two dimensions shown in Figure 1 (Stokes, 1997; Tushman \& O'Reilly III, 2007). From the dimension of 'considerations of use', the professional sector and vocational sector are in one category, as they both put emphases on practical applications. The LA\&S sector does not pay much attention to practical application, while the hybrid sector stays in the middle of the spectrum (Brint, Riddle, Turk-Bicakci, \& Levy, 2005; Carnegie Foundation for the Advancement of Teaching, 2005). However, from the dimension of 'quest for fundamental understanding', the professional sector and the vocational sector are very different. The former focuses on the training of theoretical thinking and critical thinking, while the latter pays more attention to the acquisition and mastery of operating techniques and task procedures. Such differences are also reflected in the school system. LA\&S, professions and the hybrid sector form comprehensive academic universities, while the vocational education sector independently forms vocational/technical colleges.
From the LA\&S/professional/vocational categorisation dimension, the correspondence between curriculum and career is relatively different (Wang \& Liu, 2012; Wang, Liu, Wu, \& Tsai, 2012), The LA\&S sector is in a Many-ToMany Relationship, in which one curriculum corresponds with different careers and categories, and one career corresponds with multiple curricula. Such curricula are therefore not specially designed for any specific career. Relatively, the curricula for the professions and vocational sectors are mostly designed for specific professions or careers, and the relationships between curricula and careers are One-To-One.

Due to the One-To-One Relationship, the curriculum can easily fit vocational/professional education into certain types of pathways, thus making career clusters/pathways an organising tool for curriculum design and instruction in American vocational/technical education. However, the UCAN is not only applied to the professional sector, it is also applied to the LA\&S sector and the hybrid sector in Taiwan. In terms of these sectors, the basic design logic and unit divisions of their curricula are different from the clusters/pathways. Mechanically applying the A system (one-to-one) to the B system (many-to-many) will obviously be unfair to the B system and may cause harm to it.

Using a psychology department as an example, the program can map into the pathways for mathematics and science, counselling and mental health services, human resources, marketing information management and research teaching/training, and family and community services. Psychology already has a mature course structure and curriculum division system. It uses the academic domain as the basic logic and takes basic courses (e.g., social psychology) and applied courses (e.g., organisational psychology) into consideration. If all courses are applied to 
the UCAN by force (this is the design of the UCAN system as well as the policy of TMOE's original tendency), the occupational logic and career logic of the said pathways will be different, and thus not only the entire curriculum will become fragmented, but also the curriculum design will be dragged by different occupational/career logics, thereby causing conflict and confusion (e.g., basic disciplines such as social psychology may be marginalised or ignored), which is not healthy for the long-term development of this major. In short, the first-level problem of UCAN is caused by mechanical application of the vocational sector framework on the LA\&S sector and the hybrid sector. Such inapplicability could cause harm to the long-term development of many academic fields.

The second-level problem caused by the UCAN is related to the 'quest for fundamental understanding' shown in Figure 1. The educational mode of comprehensive/academic universities emphasises know-why and focuses on the training of theoretical thinking and critical thinking, while the vocational education sector emphasises know-how and focuses on the acquisition and mastery of operational techniques and task procedures. The self-evaluated competence assessment is an important function in the UCAN. The TMOE hopes that all students in Taiwan will evaluate their mastery of the competences in their chosen occupations. The number and percentage of students who complete the online assessment serves as a key performance index of universities in Taiwan. Therefore, the content validity of the competence items is important. Competence modelling is usually classified into task orientation and worker orientation (Peterson et al., 2001). If the competence items are formulated according to task orientation, it means the work world of that occupation is largely conceptualised as consisting of standard operational procedures, technical menus and organisational routines. This kind of conceptualisation is congruent with the vocational education model. The UCAN uses this kind of conceptualisation. The competence items in the UCAN all have a task orientation. However, another way to conceptualise the work world is that it is non-menu based, knowledge-intensive and highly creative, and to conceptualise the competencies as having a worker orientation. This kind of conceptualisation corresponds with the education model of comprehensive/academic universities.

When students conduct the competence assessment of the UCAN, they will perceive the work world as being fulfilled according to operational procedures and technical routines, and they will use this image to evaluate their occupational competencies and discipline themselves by this kind of work-world image. From this point of view, the UCAN is a discipline technology. The competence assessment induces the self-discipline effect, wherein students discipline themselves as technicians, administrators or assistants (the goal of vocational education), but not as engineers, managers or professional workers (the goal of professional schools in academic universities). Those academic universities adopting the UCAN might find that the implicit work world images in the UCAN and the images taught in classrooms are very different. The students might wonder which side is wrong. Some students will determine that the school side is wrong, and that it is the source of all problems. These students may distrust the learning content offered by the school, and therefore decrease their effort in campus learning.

Consequently, the discursive truth of the educationjob gap might reproduce itself when using the competence assessment of the UCAN, thereby causing the TMOE to legitimately 'correct' the academic universities' deviations, based on a comparison to the vocational/technical education norm, regardless of the differences among the vocational/technical sector, the professional sector, or the LA\&S sector.

\section{Developing an Alternative System: CVHS}

The above section shows the problems of the TMOE's introduction of the UCAN. As we thought the problems through, we realised that the 'challenge' and 'divert' actions could only slightly decrease the adverse impact of the UCAN. We thus tried to create another kind of action, that is, to design a new IS, the Career \& Vocational Helping System (CVHS), as an alternative that would complete with the UCAN.

We considered the following in designing the new IS: (1) What kind of system is needed by a comprehensive university? (2) What do students need in these times? The resulting CVHS was institution-based and studentcentric. The CVHS has three main modules: the career exploration module, the capability development module, and the school-to-work transition module. Each module was designed based on career theory or psychology theory. For example, when designing the career exploration module, social cognitive career theory (Lent, 2005) was used to understand the users' needs and their psychological process before and after their primary career choice, while the helping tools were designed based on the theory of vocational personalities and work environments (Holland, 1997; Tien, 2010) and the theory of work adjustment (Dawis \& Lofquist, 1984). For more details of these theories, see Wang et al. (2014). Due to page limitations, we did not discuss each design theory for every module; instead, we discuss the overarching design philosophy, which corresponds to Krumboltz's learning theory of planned happenstance and career counselling (Krumboltz, 1979, 1996; Krumboltz \& Levin, 2004; Mitchell, Levin, \& Krumboltz, 1999).

\section{Career Exploration Module}

Entrance to university in Taiwan does not totally rely on the preferences expressed in the application. Some students choose or are forced to enter into departments that do not match their characteristics (incongruence between people and environment). This mismatch will influence their learning motivation, learning behaviour and 
learning outcomes (Wang \& Huang, 2010). In recent years, due to the global recession, students might bias their selection due to job concerns, thus causing this incongruence to become more serious. In addition, the unemployment rate for young people has risen rapidly and the value of educational degrees has degraded. Therefore, career anxiety becomes another problem.

The design logic of the career exploration module includes three phases. Phase 1 aims to help users understand the corresponding career space of a program to reduce their career anxiety. For instance, users select one category of program from the list, such as civil engineering, where they find several corresponding occupations. They can then select each occupation to learn more information. In phase 2, using two scales (an interests scale and a work value scale), users can understand themselves. In phase 3 , students explore the congruent/incongruent relationship between themselves and the program-based career space. For those with the problem of incongruence, they can examine the problem and search for more adaptive programs from the list. Since students are encouraged to explore different paths one by one, the system will not offer the 'best-fit' answer. The point is that if career exploration is very important for students, the IS should not just offer a quick-fix 'best fit' answer (as it does with the UCAN). Unless they devote enough effort to career exploration, students will not effectively reduce their incongruences by transferring to another department, taking dual majors, minors, or elective courses in other departments. They must think through their options in a guided manner.

\section{Capability Development Module}

In order to compensate the adverse impacts of the UCAN, the capability development module must have three features: (1) a suitable work-world image for comprehensive/academic universities, (2) support for the LA\&S sector and the professional sector, and (3) reducing the disciplinary risk caused by competence assessment. For feature 1, the module adopts a worker orientation to represent the competence needs of the job market, and then uses the same framework to represent the learning content of the university campus; while the UCAN uses a work orientation to conceptualise the job market as consisting of standard operational procedures, technical menus and organisational routines. As discussed previously, when worker orientation is adopted, the work-world images perceived by students are much like the non-menu and knowledge/creativity intensive kinds, which are more congruent with the premises of the LA\&S sector and the professions sector.

For feature 2, we developed two functions and one scale to help students clarify the relationships between learning and using. The first function was named as 'what use for what learning' (WUWL), which had a similar design logic as the UCAN. Occupational competencies that are assumed to be of use in the future were the goals for learning. However, WUWL is only one side; the other side is 'what to learn for what use' (WLWU). People will never know if what they learn now will be useful or not in future, especially in the changing and uncertain era of the 21 st century. Creativity comes from across disciplines. Knowledge in one domain may have another function in another domain. The WLWU function helps students to explore whether what they have learned may be meaningful or needed in other fields and other domains. The WLWU function is more suitable to the LA\&S students, while the WUWL function is more suitable for students in the professional sector. However, this does not mean LA\&S students can only use the WLWU function. These two functions are not mutually exclusive; they are two perspectives to deal with the complicated relationships between learning and using. Students are encouraged to use both functions to plan their career and learning activities, especially those students in the hybrid sector.

For feature 3, we abandoned the form of personal competency assessments, and instead provided five information resources for querying. The information resources included: (a) the knowledge profile of one program, which represents the competencies students would learn in the department; (b) the knowledge profile of one occupation or occupations within certain career spaces defined and selected by students; (c) the comparison between these two profiles, including the over-supply and under-supply indexes in the WUWL function; (d) the application fields and occupations when one certain knowledge domain is selected in the WLWU function; and (e) the overall curriculum resources within the university. The students could search the curriculum resources by setting one or two kinds of knowledge domains as the query conditions when exploring the under-supply gap (WUWL), or when exploring how to apply their competences in another field (WLWU).

\section{School-to-Work Transition Module}

In 4 years of study, if students can develop in an environment that supports adaptive development (the career exploration module) and have rich and diverse resources (the capacity development module), they will create a learning outcome through their personal major, minor and other experiences on campus. The learning outcome is the critical base for students to approach the workplace and the future. One of the main functions of the school-to-work transition module is to enhance the previous causal logic with effective operation. The module adopts knowledge and skill descriptors to describe and measure students' 4 years of learning outcomes. Using online scales of knowledge and skill, students evaluate their learning outcomes. Subsequently, the system compares students' self-reported knowledge and skill section with corresponding requirements in the occupations to find the most appropriate five career pathways and 20 occupations of the learning outcome. The module then constructs the common 
Table 1

Summary and Comparison of the CVHS and the UCAN

\begin{tabular}{|c|c|c|}
\hline & CVHS & UCAN \\
\hline Position & $\begin{array}{l}\text { Institution-based and student-centric design, suitable to the } \\
\text { need of comprehensive/academic universities }\end{array}$ & $\begin{array}{l}\text { Uses the logic of the vocational sector to discipline } \\
\text { comprehensive/academic universities. }\end{array}$ \\
\hline Career exploration & $\begin{array}{l}\text { Adaptive development is the main design logic. Students are } \\
\text { encouraged to explore different paths one by one; the } \\
\text { system will not offer a 'best-fit' answer. It responds to the } \\
\text { problems of student career anxiety and incongruence } \\
\text { between people and environment. }\end{array}$ & $\begin{array}{l}\text { System will offer a 'best-fit' answer. The test results show } \\
\text { students' interests in the } 16 \text { Career Clusters, which are } \\
\text { less compatible with the LA\&S sector and the hybrid } \\
\text { sector in comprehensive/academic universities. }\end{array}$ \\
\hline $\begin{array}{l}\text { Capacity } \\
\text { development }\end{array}$ & $\begin{array}{l}\text { WLWU function is as important as WUWL function: adopt a } \\
\text { worker orientation that is suitable to the work world } \\
\text { image of academic universities; support both the } \\
\text { conditions of the LA\&S sector and the professions sector; } \\
\text { reduce the disciplinary risk caused by competence } \\
\text { assessments. }\end{array}$ & $\begin{array}{l}\text { Offers personal competency assessment. The items are } \\
\text { formulated by the task orientation, wherein the work } \\
\text { worlds are conceptualised as operational procedures and } \\
\text { technical routines. These implicit images are incongruent } \\
\text { with the education model/goals of comprehensive } \\
\text { universities. }\end{array}$ \\
\hline $\begin{array}{l}\text { Work-to school } \\
\text { transition }\end{array}$ & $\begin{array}{l}\text { It measures and represents students' 4-year learning } \\
\text { outcomes and helps students define their scope of } \\
\text { employment and search for jobs. Thus, they can have a } \\
\text { better start with their learning. }\end{array}$ & $\mathrm{N} / \mathrm{A}$ \\
\hline
\end{tabular}

keywords of the occupations in CVHS. Using the external search engine Career Jet, it is possible to search for all job opportunities posted on web pages in Taiwan. Therefore, using the school-to-work transition module, students can define the scope of employment according to their 4 years of study. They can use the learning to have a better start to their career. The key point is that the UCAN assumes students' learnings are limited to their majors or limited to 'occupations', while the CVHS modules help students explore the scope of employment opportunities with what they have learned.

\section{Overarching Design Philosophy}

In the arena of educational planning and career exploration, the emphasis has been placed on goals and decision-making. In Taiwan, new entry students are supposed to have decided their major before they enter university. The expectation is that the student should have goals and be decisive even before the educational process begins. When a student experiences a career dilemma and seeks assistance from a career counsellor, the counsellor usually moves quickly to resolve the dilemma by administering a battery of tests.

However, as indicated by Krumboltz's learning theory of planned happenstance and career counselling (Krumboltz, 1979, 1996; Krumboltz \& Levin, 2004; Mitchell et al., 1999), 'chance/opportunity' and 'learning' are both important functions in many people's career development. The planned happenstance theory includes two concepts: (a) exploration generates chance/opportunities for increasing quality of life, and (b) skills enable people to seize opportunities. The most important thing that a comprehensive university can offer to students is rich chance/opportunities embedded within diverse environments. If students are open minded about their occupational goals and the competency gaps they might be able to fill, they are able to approach the vast number of new situations and changes that individuals face in a manner that encourages growth and self-development. Those opportunities and learnings may change or expand students' career trajectories in their near or long-term futures.

A good career IS for a comprehensive university to consider are such human science features (see Liu, this volume, for the epistemological reasons why). Table 1 shows the main logic of the CVHS and compares it with the UCAN. When new entry students need space for career exploration, the IS should not just offer the 'best fit' quick-fix answer (as does the UCAN). Instead, in the CVHS career exploration module, adaptive development is the main design logic. Students are encouraged to explore different paths one by one; the system will not offer a 'best-fit' answer. Second, career is not only a goal-means module. In CHVS, the capacity development module not only offers the WUWL function, it also provides the WLWU function; the UCAN only emphasises the competency gap that needs to be filled at present, and cannot imagine the future, as an intelligent thinking person may be able to. Finally, in the school-to-work transition module, the learning outcomes are not limited in the 'major' or limited in 'knowledge'. The module helps students define the scope of their employment possibilities with their overall learning. Generally speaking, in CVHS, career development not only means 'convergent' but also 'divergent' career assistance; and career assistance is about the continuous process of managing divergent-convergent-divergent pathways (see Liu, Wang, Deng, Keh, \& Lu, 2014, for similar ideas but a different implementation).

\section{Delivery and Stick With the Faith}

As mentioned above, the basic architecture of the UCAN adopts the corresponding occupation classification framework of the American vocational education system as an 
organising tool for curriculum design and instruction. However, in Taiwan, higher education is divided into two categories of general academic/comprehensive universities and vocational universities, in which the system logic of academic/comprehensive universities is totally different from the system logic of vocational universities. Therefore, we actively developed the CVHS, which is more suitable for Taiwan's higher education environment. However, the TMOE still requires the implementation of the UCAN. Career counselling units at each university must respond to the policy of the TMOE, urge students to conduct assessments on the internet, and produce much documentation to fit the changing key performance indicators (KPI) requirements. Therefore, they fail to conduct long-term thinking and planning for the overall career development direction.

At the beginning of establishing the CVHS in 2009, the development of the career information systems field was quite rare in Taiwan. The problems that were arising were complicated, and few people in the practice site had a proper understanding of it. Therefore, we began working in two directions in the hopes of breaking the exclusiveness of the UCAN's public power, which promoted the legitimacy of the system. First, we advocated problem generation based on phenomena that had never happened before, which may require special attention to the difference in temporal and spatial context. Previous practices may not be useful for present issues, and 'research' cannot be ignored, so it was necessary to engage in establishing a research foundation. Second, driven by the TMOE policy, in order to allow the CVHS to compete with the UCAN, it was necessary to fight for a free-choice space (which excluded the UCAN), which would allow universities to have another choice for a career information system. Therefore, 'political behaviour' was required and is discussed later.

First, at the 48th Annual Meeting of the Taiwanese Psychological Association, held on 26-27 September 2009, we presented the CVHS system design specifications, which showed our research-based determination in system development, and we elaborated on the usage and design of three CVHS modules. The design was in accordance with the needs of Taiwan's higher education students for career development, and each module design was based on local empirical research, in addition to referring to international literature. After launching the Capability Development Module for 1 year, we presented an evaluation report at the 2011 Annual Meeting of the Taiwan Guidance and Counseling Association. The article won the excellent paper presentation award, and will be published in the Chinese Journal of Guidance and Counseling (Wang et al., 2014). During the past 5 years, we strove to put resources into the relevant research for CVHS, including four National Science Council Research projects, three doctoral dissertations, seven masters' theses, and ten journal articles (e.g., Wang \& Huang, 2010; Wang \& Huang, 2012; Wang \& Liu, 2012; Wang et al., 2014). The above approaches were not the core element for competing with the UCAN; further, the ethical responsibilities were exhibited for CVHS users.

Second, in order to strive for a free-choice space in the universities, on the one hand we needed to be able to discuss our ideas in a public place, and to have dialogue opportunities with the UCAN to get more recognition from outside the university sphere. On the other hand, we had to obtain recognition inside the schools, as well as obtain adequate equipment, manpower and material resources support sufficient to cover the use of the CVHS in all schools. Because the four authors of this study also served as the school's administrative officers during the study period of 2009 to 2013, we were able to engage in a series of 'political behaviours'.

To obtain recognition inside schools, we actively promoted the idea with school principals and executives at all levels. Most of these principals and executives were professors in the Liberal Art department, so they were quite able to understand how the design logic of the CVHS could meet students' needs. Career counselling issues have been an important part of the Higher Education Evaluation and Accreditation system of the TMOE, so we directed the construction of the CVHS to the Evaluation and Accreditation system, in the hope it would meet the long-term development requirements of the organisation. The above actions allowed us to finally win support from the school.

To obtain recognition outside the school, we fought for the opportunity to show the CVHS prototype to senior officers from comprehensive and vocational universities during the plan review meeting of the Ministry of Education's ‘Northern Taiwan Teaching \& Learning \& Resource Center' (NTTLRC), hoping to convince the Program Review Committee to support and provide investment funds for the CVHS. It is worth mentioning that before the meeting, many committee members did not think there was a need for a new system investment - they felt the UCAN was enough. However, using the logic shown in Figure 1, we persuaded and won the favour of committee members and received a budget in December 2010 from the TMOE. The approval of this plan funding was deeply appreciated.

In order to continue to promote the legitimacy of the CVHS, it was necessary to receive more recognition from other schools. Therefore, multiple seminars were held in which administrative supervisors and career counsellors from various schools were invited to receive explanations of the CVHS's concept and architecture. A number of workshops were organised to assist various schools in training seed instructors or teaching assistants. In addition, in order to allow more schools to get to know and use the system, we built the CVHS using a cloud system and compiled training related materials as well as usage manuals and promotional materials for use by teachers and students of schools cooperating with the NTTLRC. We have also held vocational lectures with a number of universities, and engaged in site counselling and instruction. 
In addition, in order to further stabilise our external argumentation, we are more determined to strengthen the series connection between the CVHS and career counselling. Therefore, we first promoted the organisational transformation of career counselling in our school. In the past, the administrative units of career counselling in universities rarely had the positive concept of assisting students in thinking about their career development, and most of them counselled their students in a passive manner (e.g., responding to problem cases). In order to expand the popularity of the CVHS, we became more positive in constructing a miniature of the career structure and advisory assistance mechanism, based on the CVHS at our school. We also hired professional personnel to help build the students' basic concepts of exploring career-oriented learning and development, including the transformation of the role of a worker from a supporting role to professional role.

In order to promote the career advice and assistance mechanism, we cultivated the freshman focus on careers and the CVHS, and introduced the CVHS into the curriculum system. In addition, we have set up instructors and assistants for training courses, strengthened the professionalism of the career consultation mechanism, and combined the career learning activities of each school in the university, thereby further strengthening the CVHS's connection with student career development and its applicability.

During 2010-2013, we were invited by multiple universities for site explanation and to share the experience on how to perform career counselling through the CVHS. In addition, as we are committed to promoting the the CVHS concept, many of the universities visiting our university have requested the sharing of our experience on the CVHS and career counselling. This has given us more opportunities to give public explanations of our concept and be recognised by the world outside this university. In order to continue enlarging our argumentation while balancing the resources, we are planning to share our CVHS concept with additional schools other than NTTLRC partners.

\section{Action Outcome}

In Taiwan, the incongruence between person and environment is one of the main problems faced by students. Between $20-25 \%$ of students adjust their situation through transfers to another major, having dual majors, or minors. The Career Exploration Module of the CVHS aims to reinforce the adjustment. According to the primary evaluation report of the CVHS (Wang et al., 2014) regarding the success rate of major-transfers (percentage of success-transfer students over want-transfer students in one department), those departments that had introduced the CVHS had a higher success rate of major-transfers than the previous year (30\% to $50 \%$ in average), while other departments without the CVHS remained at the same rate over the
2 years, experiencing no improvement, $F(1,15)=4.397$, $p<.053$.

The user experience surveys in the Soochow University and $\mathrm{Fu}$-Jen Catholic University (FJU) show the student reactions to the systems (Figure 2). For students using the CVHS, $78 \%$ of participants thought it was helpful to their knowledge about future vocational development, and this percentage was higher than the users of the UCAN (66\%). In addition, $80 \%$ of the students using the CVHS thought it was helpful to their planning of future vocational development, and this percentage was also higher than users of the UCAN (63\%). Lastly, only $55 \%$ of the students using the UCAN thought the competence assessment functions of the UCAN had a reference value for future learning direction. This once again confirmed that the UCAN, as a tool for vocational/technical sectors, is not suitable for all students in comprehensive/academic universities.

The UCAN was introduced in April 2009, while the CVHS went online several months later. The CVHS was the first system to compete with the UCAN (they were followed by the Chinese Career Net and Young-Eagle Net). As to qualitative assessments, in the University Affair Evaluation and Accreditation of 2012, when other schools adopted the UCAN and encountered problems of suitability, the FJU Affairs Evaluation and Accreditation committee praised the contribution of the CVHS constructed by our school and suggested that 'the school guides students' career development by multiple dimensions, sets up exploration-oriented career learning and development, launches career information platforms and guidance tracking management to help students construct correct career development goals' (FJU University Affair Evaluation and Accreditation, 2012, p. 6).

Eighteen universities had adopted the CVHS by the end of 2013. If counted by the number of tested people, the number of new and real users was 9,064 people per academic year, of which nearly $60 \%$ came from other universities; only $40 \%$ were from the FJU. A total of 38,892 people were cumulatively tested in the UCAN in the past 3 years, with an average of about 12,964 people each year. If viewed according to cost-benefit analysis, CVHS funding was only one sixth of UCAN, but the number of substantive users $(9,064$ students per year) was $70 \%$ of the users of UCAN (12,964 students per year).

The success rate of major-transfer, the user experiences of two different systems, and the user population index have demonstrated the applicability of our argument. Since we have insisted on the principle of building the foundation by research and open discussion, the CVHS has become an important alternative to UCAN. Those universities that adopted the UCAN and encountered suitability problems now have another choice. Through the competition between the CVHS and the UCAN, we broke the monopoly of public authority of the UCAN, so that other universities can have more choice and perform their career education and career counselling more effectively. 


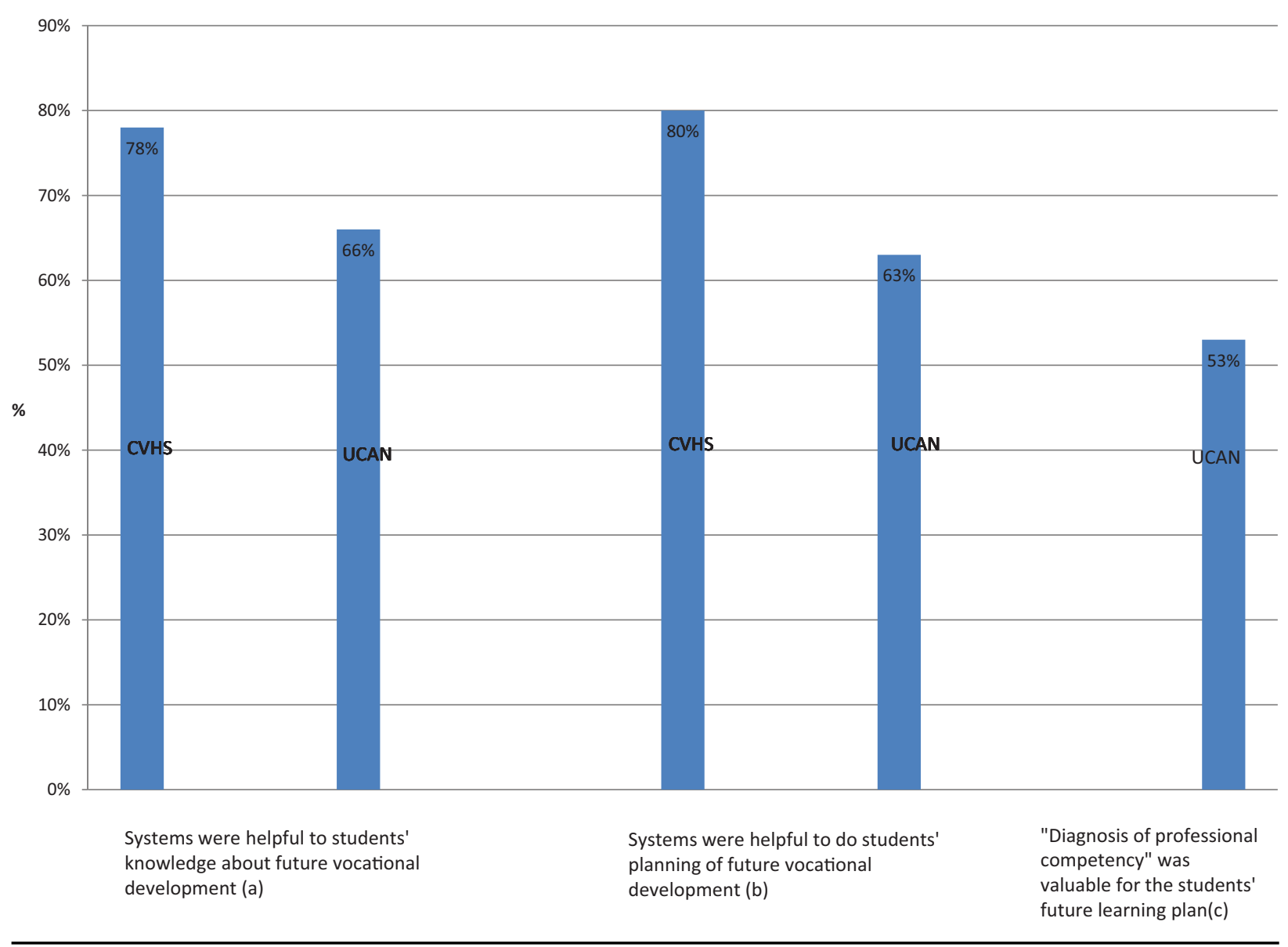

\section{Figure 2}

Students' reactions to the CVHS and UCAN systems.

Note: The UCAN surveys were conducted at the 2010 Learning Excellent Forum presented by Soochow University. The CVHS surveys were conducted in 2011 by Fu-Jen University. (a) The CVH item was: 'CVHS was helpful for their knowledge about future vocational development at their department'. The UCAN item was: 'UCAN was helpful for their knowledge about future vocational development'; (b) The CVH item was: 'CVHS was helpful for their planning of future vocational development'. The UCAN item was: 'UCAN was helpful for their planning of future employment and careers; (c) The CVHS questionnaires used 5-point scales, and the percentage was found using the weighted average.

In sum, our action in IS competition has had an impact on our society.

\section{Reflection}

Power is always subject to resistance. Those over whom power is exercised are recognised and maintained as people who act and could do otherwise (Foucault, 1981, 1982; Knights \& Morgan, 1991). Disciplinary technologies are not exclusively constraining. Instead, they open up a new and legitimate discursive space for action (Bloomfield \& Coombs, 1992). However, according to the problem we faced, the introduction of the UCAN was bound to bring subtle, negative, yet far-reaching effects on the autonomy of comprehensive/academic universities. If we handled this problem with the actions of challenge or diversion as described in the literature, we could have maintained the resistant autonomy of the individual, but the influence and scope of such individualised actions would have been relatively limited. Therefore, we suggested creating another form of action - IS competition - in which more positive social change can be created. In other words, we could design and develop a new system (the CVHS) that better fits the needs of society and users, as a replacement for government's disciplinary system (the UCAN).

Reviewing the research action, we have three reflections. First, according to the case of the UCAN versus the CVHS, the IS is a tool and plan of discursive truth. In the design and operation of self-discipline, the IS plays a critical and powerful role. In addition, the IS defines the scope and quality of discursive truth, and it strengthens and represents discursive truth and power structures. The IS has a freezing effect on truth and power. In the dynamic process of unfreezing-reconstruction-refreezing (see Lewin, 1947) through the IS, power and plans are specified and proceduralised, operationalised and rationalised. Students are disciplined to view the world through an occupational lens. When students perform self-evaluation in the UCAN, if they realise that their departments are not easily compatible with the employment market in Taiwan, they might think that the departments are the source of the gap 
between school education and practical application, and that the schools and departments should be responsible and be subject to further discipline.

In September 2009, we began to engage in gathering feedback from the academic field and to interpret the problems caused by the UCAN (please see the section of Disciplinary Technology in Higher Education), based on theories (i.e., the social cognitive career theory, the theory of vocational personalities and work environments, the theory of work adjustment, learning theory of planned happenstance and career counselling). For example, we took the first step in publishing a paper with a suggestion for the design of ISs of career guidance and counselling for university students, and initiated exchanges with professors from Beijing Normal University and Nanjing Normal University (unfreezing). From 2010 to 2011, we consulted with the facility and staff of all the departments of the FJU, prepared a report at the conference of the FJU's evaluation of core capabilities, and conducted a survey regarding the professional knowledge and capabilities of all the departments of the FJU after the conference. We provided suggestions for our school's planning and evaluation workforce in accordance with the survey mentioned above. One suggestion was that the CVHS might be able to help the schools in developing professional knowledge and core capabilities (reconstruction). Soon after, we began to contact the convener of the freshman-required courses program, and attended workshops for teachers, in which we explained what the role of the CVHS. Thus a model of cooperation between CVHS and the required courses program has been initiated (refreezing).

In addition, we completed an initial report regarding the CVHS in the school's affairs evaluation meeting, and illustrated how we should employ a professional knowledge and capabilities survey for an evaluation of departments and graduate institutes. We have delivered speeches in many departments and workshops. Meanwhile, we were invited by the curriculum affairs committee to attend the meeting for a curriculum information system, in which we proffered the initial design of the 'FJU Curriculum Information System' for their reference (refreezing).

From 2011 to 2013, we have reached out to students and conducted numerous surveys in order to better understand what students think about this matter. We also collected data from a number of sources, such as a survey of professional knowledge and capabilities of all FJU departments, as well as graduate surveys. We consulted with other universities and took part in various projects. In addition to taking part in mid-term and end-of-term seminars, we opened our system to other colleges and universities, initiated a tour of promotional activities among campuses, and helped to institute the CVHS and other career-development courses according to each college's demands and needs.

As for the CVHS, in order to break through the freezing state constructed by policy statements and the power and information technology of the state, we were convinced that discourse analysis was insufficient. We regarded the ICTs or the IS as forms of social action. By competition between ISs, we thought we might break through the hegemony of policy statements, power and state technology. An outcome of the CVHS, as indicated by our qualitative and quantitative assessments, is that is is able to change society - at least, that aspect of society represented in the university. Due to our continuing diligence in employing the CVHS in a cooperative manner with Chinese Career Net (CCN) and Young-Eagle Net (YEN) (for other alternative ISs from other universities, see Liu et al., 2014), it is said that in 2014 the TMOE will modify and reposition the UCAN. Perhaps this result is due to the competitive action between the UCAN and other university systems developed through the cooperation of the CVHS, the CCN and the YEN.

Culture is the centrepiece of the attempt to understand unity in the diversity of human beings. Liu and Liu (2003) indicated that Confucian philosophy is suitable for exploiting both an epistemology and practice that are ideal for the social science (see also Liu, 2014). Culture in Taiwan is influenced by Confucianism, which values ethics and reason. However, this belief system has been gradually transformed into one of strict social status and ranking. Therefore, we suggest that 'the respect for seniority', 'scholars, farmers, artisans and merchants - social status and ranking' and 'the worthiness of other pursuits is small, while the study of books excels them all' leads people in Taiwanese culture to accept a ranking system at face value (C. Liu, 2013). Therefore, Taiwanese people seemingly respect pluralistic values; however, in terms of cultural habits, they often have regard only for a single hierarchical value ranking where formalism has become popular.

The TMOE considers immediate employment as the unit of value in its formalism. Hence, all colleges and universities in Taiwan were required to adopt the UCAN and support various evaluation mechanisms designed to legitimise it. However, given their predilection towards formalism, universities might simply try to pass the evaluation standards set by the TMOE and they might not seriously question the assumptions of the UCAN. Basic questions, such as whether the assumptions and measures of the tool are appropriate, were not asked in many universities. Many departments for which the measurements and assumptions were inappropriate seemed helpless to resist other than by complaining.

Therefore, we challenged the foundation of the UCAN. Past literature has indicated two possible actions: challenge or divert. However, although the 'challenge' and 'divert' actions can protect individuals' resistant autonomy, their overall effect and scopes are limited. Therefore, we engaged in a third action - IS competition - in which more positive and pervasive social changes can be created. Each module of the CVHS was designed based on career theories or psychology theories. IS innovation should not 
be based only on technical and rational perspectives, it must be concerned with the value, benefits and power of the IS for different groups.

Finally, in our action research from 2009-2013, we undertook positions as administrative supervisors in the FJU. In these positions within our university, we could engage in career consultation assistance, including collecting integrated information about programs. Liu and Liu (2003) advocated that the model society in traditional East Asia is harmonious, that the ruler looks after the people, and the people respect the ruler. At each level, such an unequal but reciprocal system of exchange serves to maintain order. Outside the university, we continued expanding external resources and connections with other institutions. Not everyone has the resources to create new ISs to compete with a state-sponsored technology. However, we and others have ashown that the threshold is not too high. The plurality of ISs now available in the Taiwanese environment enhances the diversity of management styles in the tertiary sector and reinforces the action capacity of citizen groups and academic communities. Although there is a cost threshold to create an IS as a social action, the implications of such actions are important. We hope that other citizen groups and academic communities will continue to recognise the importance of undertaking such actions in the future.

\section{References}

Avgerou, C., \& McGrath, K. (2007). Power, rationality, and the art of living through socio-technical change. MIS Quarterly, 31(2), 295-315.

Bloomfield, B.P., \& Coombs, R. (1992). Information technology, control and power: The centralization and decentralization debate revisited. Journal of Management Studies, 29(4), 459.

Brint, S., Riddle, M., Turk-Bicakci, L., \& Levy, C.S. (2005). From the liberal to the practical arts in American colleges and universities: Organizational analysis and curricular change. The Journal of Higher Education, 76(2), 151-180.

Carnegie Foundation for the Advancement of Teaching (CFAT) (2005). The Carnegie Classification of Institutions of Higher Education: 2005 edition. USA: Carnegie Publications. Retrieved March 1, 2011 from the http://classifications.carnegiefoundation.org/descriptions/

Dawis, R.V., \& Lofquist, L.H. (1984). A psychological theory of work adjustment. Minneapolis: University of Minnesota Press.

Doolin, B. (1998). Information technology as a disciplinary technology: Being critical in interpretive research in information systems. Journal of Information Technology, 13, 301-312.

FJU University Affair Evaluation and Accreditation. (2012). Retrieved from http://www.heeact.edu.tw/ sp.asp?xdurl=appraise/appraiseData_list9.asp\&ctNode $=$ 1857\&ctUnitId $=1133 \& \mathrm{mp}=2$

Foucault, M. (1981). The history of sexuality: An introduction. London: Penguin.
Foucault, M. (1982). The subject and power. In H.L. Dreyfus \& P. Eabinow (Eds.), Michel Foucault: Beyond structuralism and hermeneutics (pp. 208-226). New York: Harvester Wheatsheaf.

Frank, J.R., Mungroo, R., Ahmad, Y., Wang, M., De Rossi, S., \& Horsley, T. (2010). Toward a definition of competency-based education in medicine: A systematic review of published definitions. Medical Teacher, 32(8), 631637.

Harvey, L. (2001). Defining and measuring employability. Quality in Higher Education, 7(2), 97-109.

Holland, J.L. (1997). Making vocational choices: A theory of vocational personalities and work environments. Odessa, FL: Psychological Assessment Resources.

Kehm, B. (2010). Quality in European higher education: The influence of the Bologna process, Change, 42(3), 42-46.

Knights, D., \& Morgan, G. (1991). Corporate strategy, organizations, and subjectivity: A critique. Organization Studies, 12(2), 251-273.

Krumboltz, J.D. (1979). A social learning theory of career decision making. In A. Mitchell, M.G.B. Jones, \& J.D. Krumboltz (Eds.), Social learning and career decision making (pp. 19-49). Cranston, RI: Carroll Press.

Krumboltz, J.D. (1996). A learning theory of career counseling. In M.L. Savickas \& W.B. Walsh (Eds.), Handbook of career counseling theory and practice (pp. 55-80). Palo Alto, CA: Davies-Black Publishing.

Krumboltz, J.D., \& Levin, A.S. (2004). Luck is no accident: Making the most of happenstance in your life and career. Atascadero, CA: Impact Publishers.

Lent, R.W. (2005). A social cognitive view of career development and counseling. In S.D. Brown \& R.W. Lent (Eds.), Career development and counseling: Putting theory and research to work (pp. 101-127). Hoboken, NJ: John Wiley \& Sons.

Lewin, K. (1947). Group decision and social change. In T.M. Newcomb \& E.L. Hartley (Eds.), Human relations in curriculum change (pp. 39-44). New York: Henry Holt \& Co.

Liu, C. (2013). Why do we need reforming social value? Research in Applied Psychology (in Chinese), 59, 1-9.

Liu, J.H. (2014). What Confucian philosophy means for Chinese and Asian psychology today: Indigenous roots for a psychology of social change. Journal of Pacific Rim Psychology, 8(2), $35-42$.

Liu, J.H., \& Liu, S.H. (2003). The role of the social psychologist in the 'Benevolent Authority' and 'Plurality of Powers' systems of historical affordance for authority. In K.S. Yang, K.K. Hwang, P.B. Pedersen, \& I. Daibo (Eds.), Progress in Asian social psychology: Conceptual and empirical contributions (pp. 43-66). Westport, CT: Praeger.

Liu, S., Wang, C., Deng, C., Keh, F., Lu, Y., \& Tsai, Y. (2014). Action research using a career model of the Chinese wisdom of 'classic of changes' and its applications. Journal of Pacific Rim Psychology, 8(2), 83-94.

Mitchell, K.E., Levin, A.S., \& Krumboltz, J.D. (1999). Planned happenstance: Constructing unexpected career 
opportunities. Journal of Counseling \& Development, 77, 115124.

Peterson, N.G., Mumford, M.D., Borman, W.C., Jeanneret, P.R., Fleishman, E.A., Levin, K.Y., ... Dye, D. (2001). Understanding work using the occupational information network (O*NET): Implications for practice and research. Personnel Psychology, 54, 451-492.

Stokes, D.E. (1997). Pasteur's quadrant: Basic science and technological innovation. Washington, DC: Brookings Institution Press.

Tien, H. (2010). Cultural encountering: The applicability of Holland's typology in Taiwan. Asian Journal of Counseling, 16(2), 193-226.

Tushman, M., \& O’Reilly III, C. (2007). Research and relevance: Implications of Pasteur's quadrant for doctoral programs and faculty development. Academy of Management Journal, 50(4), 769-774.

Wang, H.H., \& Huang, C.C. (2010). The application of selfdetermination theory on students' career choice and learning outcomes under the multiple college admission system. Journal of Research in Education Sciences (in Chinese), 55(2), $1-27$.
Wang, S.F., \& Huang, S.W. (2012). Program breadth-depth characteristic \& school-work correspondence characteristic: Moving from typological theory to characteristical theory. Psychological Testing [in Chinese], 59(2), 277-301.

Wang, S.F., \& Liu, , C.M. Liu (2012). The crosswalk between occupational classification and educational classification: Building the relational descriptors of programmes groups. The Archive of Guidance \& Counseling [in Chinese], 34(1), 1-29.

Wang, S.F., Liu, C.M., Wu, B.J. \& Tsai, C.L.(2012). Out of the ivory tower! But where to go? A policy analysis by the perspective of school-to-work transition. Interlocution: University and Social Engagement [in Chinese], 1. Retrieved from http://interlocution.tw/publication/RA/Paper_ bQCimbNN01.pdf

Wang, S.F., Wu, J.B., Shiahhou, H.P., Liu, S.H., Wu, R.L., Chou, C.M., \& Tsai, C.L. (2014). An evaluation study of CVHSM1 career information system: Career behavior, guidedance implementation \& impact. Chinese Journal of Guidance and Counseling [in Chinese], 40, 97-128.

Willcocks, L.P. (2006). Michel Foucault in the social study of ICTs: Critique and reappraisal. Social Science Computer Review, 24(3), 274-295. 